\title{
A multiple performance analysis of market-capacity integration policies
}

\author{
Ahmed M. Deif* \\ Department of Industrial and Service Engineering, \\ Nile University, Cairo, Egypt \\ E-mail: deif@nileuniversity.edu.eg \\ ${ }^{*}$ Corresponding author
}

\section{Hoda A. EIMaraghy}

Intelligent Manufacturing Systems Research Centre (IMS),

Industrial and Manufacturing Systems Engineering Department,

University of Windsor,

ON, Canada, N9B 3P4

\begin{abstract}
A model that uses simulation augmented with Design of Experiments (DOE) is presented to analyse the performance of a Make-to-Order (MTO) reconfigurable manufacturing system with scalable capacity. Unlike the classical capacity scaling policies, the proposed hybrid capacity scaling policy is determined using multiple performance measures that reflect cost, internal stability and responsiveness. The impact of both tactical capacity and marketing policies and their interaction on the overall performance was analysed using DOE techniques and real case data. In addition to the different insights about the trade-offs involved in capacity planning decisions, the presented results challenged the conventional capacity planning wisdoms in MTO about the negative role of the capacity scalability delay time. Finally the analysis demonstrated the importance of inter-functional integration between capacity and marketing policies.
\end{abstract}

Reference to this paper should be made as follows: Deif, A.M. and ElMaraghy, H.A. (2011) 'A multiple performance analysis of market-capacity integration policies', Int. J. Manufacturing Research, Vol. 6, No. 3, pp.191-214.

Biographical notes: Ahmed M. Deif received his $\mathrm{PhD}$ and MASc in Industrial and Manufacturing Systems Engineering from the University of Windsor in 2006 and 2003, respectively. He received his BSc from The American University in Cairo, 1999. He is currently an Assistant Professor at the University of Regina. His research interests are in manufacturing capacity management, manufacturing planning and control and dynamic analysis of manufacturing systems. He is a Research Affiliate of the International Academy for Production Engineering (CIRP), Senior Member of the Society of Manufacturing Engineers (SME) and Member of the Institute of Industrial Engineers (IIE). 
Hoda A. ElMaraghy, PhD, PEng is currently Canada Research Chair in Manufacturing Systems, Professor of Industrial and Manufacturing Systems Engineering and Director of the IMS Centre at the University of Windsor. She is a Fellow of the CSME, Fellow of SME, and Fellow of the CIRP and Member of the ASME. Her teaching and research interests are in manufacturing systems design, modelling, flexibility, reconfiguration, control, quality, inspection, assembly, process planning and robotics. She published more than 350 papers, edited two books and contributed to 13 others. She received a Mechanical Engineering Bachelor Degree from Cairo University, Egypt and Master's and PhD Degrees from McMaster University, Canada.

\section{Introduction}

Demand uncertainty, global economic competition and rapid social and technological changes have forced manufacturing to face a new economic objective: manufacturing responsiveness, i.e., the ability of a manufacturing system to respond to disturbances which impact upon production goals and consequently, its ability to adapt to changing market conditions. In the early 1990s the idea of agile production systems was pursued, enabling short changeover times between manufacturing different products. Since the end of the 1990s a new Reconfigurable Manufacturing System (RMS) paradigm has emerged; these systems are capable of being quickly adapted to changing market requirements by providing the needed functionality and capacity when needed and where needed (Koren et al., 1999). RMS aims to enhance manufacturing responsiveness in the production of low-cost and high-quality products. The key characteristics of RMS, which enable these systems to achieve their goals, are modularity, integrabilty, convertibility, customisation and diagnosability (Mehrabi et al., 2000). Other enablers include reconfigurable process planning and changeable production planning and control systems (ElMaraghy, 2005; Wiendahl et al., 2007).

Dynamic capacity planning in these RMSs is becoming a more challenging problem. The technological advancement on the operational level, which enabled the ease of capacity scalability, is not sufficient to guarantee high level of overall enterprise performance. Recent literature has often advocated the need for stronger inter-functional integration in manufacturing operations. This is highly recognised when considering the interface between marketing and operational or production strategies (Ulsoy and Yazgac, 1995). Kotha and Swamidass (2000) found that a fit between certain dimensions of market strategy and advanced manufacturing technology was associated with superior performance. Shapiro (1977) pioneered the discussion of the production/marketing co-ordination and proposed a framework identifying eight areas of necessary co-operation but potential conflict within the marketing/production interface. Among the different cooperation areas is the interface between market and capacity management policies.

Both strategic and tactical problem areas are becoming extremely important in today's competitive environment. Managing dynamic capacity (as a tactical activity) cannot be done in isolation from the market plan (as a strategic activity). Deciding on the best capacity scaling policy is another challenge that faces the capacity planner for these modern systems. Classically, cost and time were the typical performance measures used 
to evaluate different capacity scalability policies. However, in today's dynamic environment with the need to maintain high performance at both the production as well as the market fronts, multiple performance measures are needed.

This paper investigates the impact of different capacity scaling policies (as an important tactical decision) together with different responsiveness levels (as a key marketing strategy decision) on the system overall performance. Performance refers to the WIP level, capacity level and backlog level as multiple measures for both production as well as market performance. In addition, the analysis goes beyond the impact of the previous indigenous parameters to examine also the impact of demand uncertainty as the major exogenous factor that affects the manufacturing system's performance.

The presented approach is built on the model developed by Deif and ElMaraghy (2007) for modelling the dynamics of the capacity in an RMS for a Make-to-Order (MTO) facility using system dynamics. The model is modified to include stochastic demand rather than deterministic demand. Factorial Design of Experiment (DOE) analyses are conducted for the identified indigenous and exogenous parameters to gain a thorough understanding of their impact on the performance measures as well as their interaction. In addition, the best capacity-marketing policy to be adopted for different demand scenarios is examined.

\section{Literature review}

The capacity scalability problem is classically addressed from a static view point as the problem of capacity expansion to meet increasing demand at a minimum cost. Manne Alan (1967) conducted the first study of the capacity expansion problem. Extensive review of the classical capacity expansion problem can be found in Luss (1982). However, in today's market, manufacturing systems are typically faced with a rapidly changing and uncertain demand together with continuous advancement of technology; thus, the need to address the capacity scalability problem from a dynamic view point is becoming more obvious. System Dynamics (SD) developed by Forrester (1961) is among the dynamic approaches that has been used to model and analyse dynamic systems and applied to the dynamic capacity management problem. SD aims at understanding the interaction among the physical process, the information and the managerial policies of capacity scalability.

Examples of manipulating SD models to tackle the capacity planning needs include an attempt by Evans and Naim (1994) that aimed at developing an SD model for supply chains with capacity constraints and studying the effect of capacity constraints on the system's performance and overall cost.

Tomlin (1999) analysed capacity investments in single-product supply chains in which the participants make investments decisions to maximise their individual profits. Multi-products were also investigated, but the proposed solution only considered demand patterns that assure an upper bound on stock out.

Helo (2000) suggested a capacity-based supply chain model that includes a mechanism for handling the trade-off between lead-time and capacity utilisation. It was shown that this capacity analysis, including surge effects, in supply chains would improve their responsiveness.

Higuchi and Troutt (2004) developed an SD model that linked product diffusion with product availability. They showed that capacity planning is crucial for market success of 
an innovative product that is characterised by a short life cycle. Kamath and Roy (2007) proposed another system dynamic model to study capacity augmentation also in short life cycle products. They studied how to obtain the right structure, by changing the system elements and their interactions to increase profit and investigated the effect different forecasting models on system performance.

Goncalves et al. (2005) highlighted the issue of capacity variation in their push-pull manufacturing SD model through the effect of capacity utilisation on the production start rate and demonstrated the effects of sales and production interaction on destabilising the system and degrading its performance.

Anderson et al. (2005) considered logical capacity scalability in supply chains for service and custom manufacturing. They showed the effect of reducing lead-time and sharing the demand information on improving the system performance. In addition, they proposed some polices to handle and reduce backlog in these systems.

Vlachos et al. (2007) proposed a model to study the long-term behaviour of reverse supply chains applied to remanufacturing. For that purpose, they examined efficient remanufacturing and collection capacity expansion policies that maintain profit while considering direct and indirect factors.

Deif and ElMaraghy (2007) proposed an SD model for capacity scalability in MTO manufacturing. They used various performance measures to examine the best scaling policy under different demand scenarios. They showed that the best scalability policy would be based on both the marketing strategy as well as the operational production objectives.

Deif and ElMaraghy (2009) developed a multi-stage production system model based on SD to examine the impact of operational complexity sources on the capacity management problem. They referred to operational complexity as the uncertainty associated with demand, lead time and Scalability Delay Time (SDT) managing dynamic capacity. The presented results illustrated the direct relation between operational complexity and uncertainty especially that associated with the internal-stage lead time.

The presented work modifies the model developed by Deif and ElMaraghy (2007) and proposes a generalised understanding of integrating market and capacity scalability policies. The presented work differs from the previous related dynamic capacity management research by focusing on multiple performance measures rather than the typical single performance measure to study the best capacity scalability policy. In addition, a detailed analysis for the interaction and the impact of some indigenous and exogenous parameters on market-capacity policies in MTO reconfigurable systems is presented for the first time.

\section{Model description}

The development of an appropriate model for dynamic capacity scalability, which integrates the marketing demand and marketing policies, is an essential step for the intended analysis. Figure 1 shows a system dynamic model for dynamic capacity scalability in MTO reconfigurable systems. The model expresses the capacity as a stock level (following SD terminology) controlled by scaling rate. This dynamic representation of the scaling process is suitable for capturing the ability of RMS to adjust their 
capacity and, hence, makes the model a valid representation for these systems. In addition, the model incorporates the WIP, inventory and backlog levels of the system as other performance measures that are involved in the scalability process as well as being used to evaluate the overall system performance. Finally, the model captures the stochastic nature of today's demand and the marketing responsiveness policy represented in the Target Responsiveness Time (TRT). It is important to note that the developed model is designed for the MTO industries. The model logic is explained in the following section while more details can be found in Deif and ElMaraghy (2007).

Figure 1 Model structure for capacity scalability in RMS (see online version for colours)

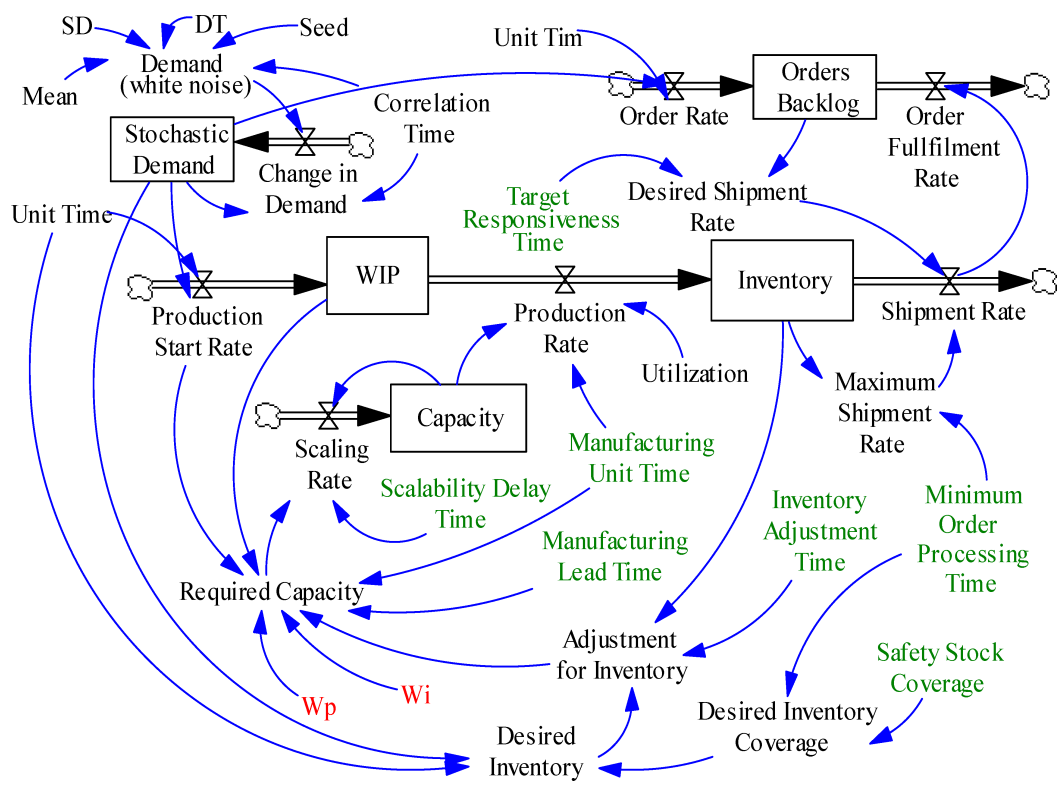

In this paper, a continuous-time model is used because it provides an acceptable approximation of the continuous capacity scalability process in RMS at that level of abstraction and aggregation. Both the operations management and SD literature support the use of continuous models for capacity planning (e.g., Anderson et al., 2005; Sethi and Thompson, 2000; Holt et al., 1960). Finally, similar dynamic characteristics can be obtained using discrete-time models (John et al., 1994). Deterministic data is used in the analysis to provide a simple yet effective comparison between the various scenarios.

\subsection{Model nomenclature}

Let

\begin{tabular}{lll}
\hline$C i(t)$ & $=$ & capacity level at time $t$ \\
$B(t)$ & $=$ & backlog level at time $t$ \\
$I(t)$ & $=$ & inventory level at time $t$ \\
\hline
\end{tabular}




\begin{tabular}{|c|c|c|}
\hline$W I P(t)$ & $=$ & WIP level at time $t$ \\
\hline$P R(t)$ & $=$ & production rate at time $t$ \\
\hline $\operatorname{PSR}(t)$ & $=$ & production start rate at time $t$ \\
\hline$A D(t)$ & $=$ & average demand at time $t$ \\
\hline$C T$ & $=$ & $\begin{array}{l}\text { correlation time. This constant captures the degree of inertia (dependence) in } \\
\text { noise process }\end{array}$ \\
\hline$S D$ & $=$ & standard deviation for the normal demand distribution \\
\hline$D T$ & $=$ & time step \\
\hline Seed & $=$ & the seed for randomly generated varieties of the stochastic demand data \\
\hline$O R(t)$ & $=$ & the order rate at time $t$. Note that $\mathrm{OR}(\mathrm{t})$ equals customer order at time $t$ \\
\hline $\operatorname{ShR}(t)$ & $=$ & shipment rate at time $t$. It is the rate of physical product leaving the system \\
\hline $\operatorname{OFR}(t)$ & $=$ & $\begin{array}{l}\text { the order fulfilment rate at time } t \text {. This rate presents the information flow of } \\
\text { the products leaving the system }\end{array}$ \\
\hline$T R T$ & $=$ & $\begin{array}{l}\text { the target responsiveness time. It represents the manufacturer's goal for the } \\
\text { interval between placement and receipt of orders }\end{array}$ \\
\hline $\operatorname{DSR}(t)$ & $=$ & the desired shipment rate at time $t$ \\
\hline $\operatorname{MSR}(t)$ & $=$ & $\begin{array}{l}\text { the maximum shipment rate at time } t \text {. It depends on the system's current } \\
\text { inventory }\end{array}$ \\
\hline$M O P T$ & $=$ & $\begin{array}{l}\text { the minimum order processing time. It represents the minimum time required } \\
\text { to process and ship an order }\end{array}$ \\
\hline$S S C$ & $=$ & $\begin{array}{l}\text { the safety stock coverage time. It is the time required to cover unexpected } \\
\text { variation in demand (the higher this value, the greater the service level) }\end{array}$ \\
\hline$D I C$ & $=$ & $\begin{array}{l}\text { the desired inventory coverage time. It is the time required to cover shipments } \\
\text { during the expected rate }\end{array}$ \\
\hline$I A T$ & $=$ & $\begin{array}{l}\text { the inventory adjustment time. It is the time required to react for inventory } \\
\text { discrepancy between the current inventory level and the desired level }\end{array}$ \\
\hline$D I(t)$ & $=$ & the desired inventory level at time $t$. It is based on customer demand \\
\hline$A I(t)$ & $=$ & the adjustment for inventory rate at time $t$ \\
\hline$U$ & $=$ & the utilisation level of the available capacity \\
\hline$R C(t)$ & $=$ & required capacity at time $t$ at stage $I$ \\
\hline$S D T$ & $=$ & scalability delay time \\
\hline$S R(t)$ & $=$ & scalability rate at time $t$ \\
\hline$M L T$ & $=$ & manufacturing lead time. It is the time required to process products \\
\hline MUT & $=$ & manufacturing unit time \\
\hline$W_{i}$ & $=$ & the relative weight of inventory consideration in capacity scalability decision \\
\hline$W_{p}$ & $=$ & the relative weight of demand consideration in capacity scalability decision \\
\hline
\end{tabular}

\subsection{Model logic}

\subsubsection{Stochastic demand modelling}

The demand in this model is assumed to have a continuous cumulative Normal Distribution Function. Huh et al. (2006) state that demand should have a continuous distribution because demand is inherently continuous; the variance in demand is often 
high and finally, because continuous demand distribution may generate a more robust capacity plan than finite number of discrete scenarios. Equation (1) formulates the demand as white noise with a normal distribution.

$$
\text { White Noise }(t)=A D(t)+\left[S D^{2} * \frac{(2-(D T / C T))}{(D T / C T)}\right]^{0.5} * \operatorname{Normal}(0,1, \text { Seed }) \text {. }
$$

Equations (2) and (3) display the values for the demand pink noise and the change in demand pink noise, respectively

Pink noise $(t)=$ Change in pink noise - pink noise ${ }_{0}$.

\subsubsection{Capacity scalability planning and control}

Capacity scalability decisions are controlled through the scaling rate (equation (3)).

$$
\dot{C}(t)=S R(t)
$$

The equation for the scaling rate is determined by the required capacity together with the scalability delay (equation (4)).

$$
S R(t)=\frac{C(t)-R C(t)}{S D T} .
$$

The required capacity (equation (5)) has three components and each component reflects a planning and control policy.

$$
R C(t)=\left[\left(W_{p}^{*} P S R(t)\right)+\left(W_{i}^{*} A I(t)\right)+\left(\left(1-W_{p}-W_{i}\right) * \frac{W I P(t)}{M L T}\right)\right] * M U T
$$

where $0 \leq W_{p} \leq 1$ and $W_{p}+W_{i} \leq 1$.

The $R C(t)$ is defined in this manner to allow change and adaptation to the capacity scalability policy based on various marketing and operational objectives through manipulating $W_{p}$ and $W_{i}$. One policy can be based on just chasing the demand. This is achieved by setting $W_{p}$ equal to zero so that production is dedicated only to chase the demand. Another policy can be inventory-based where the required capacity is controlled by inventory adjustments. Inventory adjustment refers to the filling rate used to compensate for the discrepancy between the current inventory level and the required inventory level (the later is usually determined based on the service level set by the marketing strategy). This can be achieved by setting $W_{i}$ equal to zero. A third policy is WIP-based where the capacity is changed to keep $W I P$ at a constant level. The change in the WIP level is based on little's law (WIP = Production Rate $\times M L T$, Sterman 2000) where $R C$ replaces the production rate. This can be achieved by setting $W_{i}$ equal $W_{p}$ equal to zero. Integrating the three main parameters (demand, inventory and WIP levels) and manipulating their interaction through the values of the different weights involved in this equation, captures the dynamics of capacity scalability of RMS in a MTO environment and referred to as the hybrid policy. The analysis in this paper focuses on the hybrid policy. 


\subsubsection{Inventory control}

The inventory control mechanism in the developed model follows the same one introduced by Sterman (2000). The inventory adjustment is controlled by the inventory gap between desired and current inventory levels (equation (6)).

$$
A I(t)=\frac{D I(t)-I(t)}{I A T} .
$$

The desired inventory level is calculated using equations (7) and (8) to ensure enough coverage of products for the anticipated demand.

$$
\begin{aligned}
& D I(t)=C O(t) * D I C \\
& D I C=M O P T+S S C .
\end{aligned}
$$

The desired inventory coverage includes two components: First, the manufacturer should maintain enough coverage to ship at the expected rate requiring a base coverage level equal to MOPT. Second, to ensure an adequate level of service, the manufacturer adds Safety Stock Coverage (SSC).

The current inventory level is controlled by equation (9).

$$
\dot{I}(t)=P R(t)-S h R(t) .
$$

\subsubsection{Production control}

The WIP level is determined by the difference between the production start rate and the actual production rate (equation (10))

$$
W \dot{P}(t)=P S R(t)-P R(t) .
$$

The production start rate is set to be equal to the stochastic demand (equation (11)). The production rate is controlled by the capacity scalability level, as this is the typical case in RMS where recent technological solutions allow frequent capacity changes. Such a characteristic was the reason behind modelling the logic of the production control to be dependent on capacity scaling and then directly relating that scaled level of capacity to the production level. However, for practical considerations, the capacity is factored by the real system utilisation level (equation (12)) to account for variations between the two levels. It should be noted that the calculation of the utilisation level is beyond the scope of this paper and is taken as an input.

$$
\begin{aligned}
& P S R(t)=C O(t) \\
& P R(t)=\frac{C(t)^{*} U}{M U T} .
\end{aligned}
$$

\subsubsection{Customer orders fulfilment}

The customer orders are fulfilled by the order fulfilment rate, which is controlled by the shipment rate (equation (13)). The shipment rate is given by the minimum of either the 
desired shipment rate or the maximum shipment rate (equation (14)). This is the case for MTO industries considered in this work; however, make-to-stock industries can adopt the same model by maximising rather than minimising equation (14)

$$
\begin{aligned}
& \operatorname{OFR}(t)=\operatorname{ShR}(t) \\
& \operatorname{ShR}(t)=\operatorname{Min}(\operatorname{DSR}(t), \operatorname{MSR}(t)) .
\end{aligned}
$$

The desired shipment rate is calculated as a function of the current backlog and the TRT (equation (15)). In the RMS paradigm, the responsiveness time is a major performance measure of these responsive systems and tends to be low.

$$
\operatorname{DSR}(t)=\frac{B(t)}{T R T} .
$$

The backlog level is calculated as the difference between the order rate (which is exactly equal to the customer orders as in equation (16)) and the order fulfilment rate (equation (17)). In RMS systems, backlog is supposed to be at a low level; practically however, it cannot be zero.

$$
\begin{aligned}
& O R(t)=C O(t) \\
& \dot{B(t)}=O R(t)-O F R(t) .
\end{aligned}
$$

The maximum shipment rate is determined by the available inventory level and the minimum order processing time (equation (18))

$$
\operatorname{MSR}(t)=\frac{I(t)}{M O P T} .
$$

\section{Numerical experiments and application}

The developed model as investigated by Deif and ElMaraghy (2007) showed that the hybrid capacity scaling policy, where the demand, inventory and WIP are considered simultaneously when adjusting the capacity scalability level, is the best policy to use with fluctuating demand. This is achieved by setting $W_{i}$ and $W_{p}$ to have different values reflecting the relative importance of different performance measures. However, setting the best values of these weights requires a clear understanding of their impact on the performance measures as well as how they interact with other parameters, in particular the parameters that reflect the demand nature and marketing policy. Thus, to gain insights about the impact of marketing policy together with the capacity scaling policy on the system performance, a DOE approach is employed in this analysis.

The DOE consists of simulating two levels for the parameters shown in Table 1. The parameters are chosen to reflect the capacity scaling policy $\left(W_{i}\right.$ and $\left.W_{p}\right)$ and the marketing policy (TRT) because their impact on the overall performance is of interest. In addition, the SDT and the demand variation (Standard Deviation (SD)) are included in the experimental design because they have the potential to interact with the previous parameters. The performance measures used for the assessment are: 
1 the capacity level since this level with its filling rate reflects the scaling effort and cost

2 WIP level to reflect manufacturing stability

3 backlog level to reflect responsiveness of the system.

The inventory is not included as it is not a critical performance measure for a make to order manufacturing environment.

Table 1 DOE parameters and their values

\begin{tabular}{lccccc}
\hline Level & & & & & \\
\hline Low & $W_{p}$ & $W_{i}$ & TRT & $S D T$ & $S D$ \\
High & 0.25 & 0.25 & 1 & 1 & 1000 \\
\hline & 0.5 & 0.5 & 3 & 2 & 5000 \\
\hline
\end{tabular}

The parameter levels for the weights provide a broad range, which represents various capacity scaling policies. The SD of the stochastic demand has a lower value of $10 \%$ of the mean value reflecting a less variable demand and a high value of $50 \%$ of the mean value representing a high demand variation. The SDT varies to reflect the different scaling options on both the machine as well as the system level. Finally, the TRT varies to reflect high responsiveness marketing policy (1 week) and a lower one (3 weeks).

The values of the other parameters used in are shown in Table 2 . The selected values for the different time parameters are based on a case study of MTO furniture manufacturing company. The company, which adopts a RMS and located in the USA, manufactures sofas and chairs to order. It receives average orders of 10,000 per week and has a delivery spectrum from 1 to 3 weeks (TRT). The model is initialised at equilibrium (i.e., the initial values of the WIP, capacity, inventory and backlog levels are set to the target values (Sterman, 2000) and simulated for 50 weeks in each run.

Table 2 Values of the base case parameters

\begin{tabular}{lcc}
\hline Parameter & Value & Unit \\
\hline Demand mean & 10000 & Parts \\
Time step & 0.125 & Weeks \\
Manufacturing Lead Time (MLT) & 1 & Weeks \\
Inventory Adjustment Time (IAT) & 2 & Weeks \\
Minimum Order Processing Time (MOPT) & 1 & Weeks \\
Safety Stock Coverage (SSC) & 1 & Weeks \\
Utilisation level (U) & $100 \%$ & N/A \\
Manufacturing Unit Time (MUT) & 1 & Weeks \\
\hline
\end{tabular}

A half factorial DOE analysis is conducted (16 runs). This experimental design is justified since in the majority of manufacturing applications (including this case study) the assumption of having the third and upper interaction parameters as insignificant is highly valid. Thus, a half factorial analysis will result in a fifth resolution experiment, which guarantees that no confounding will occur between main parameters and 
second-order interaction parameters. The half factorial runs and the measured results of the average capacity, WIP and backlog levels are listed in Table 3.

Table 3 Measured results of the average capacity, WIP and backlog levels

\begin{tabular}{llllcclll}
\hline & $W_{p}$ & $W_{i}$ & $S D$ & TRT & SDT & \multicolumn{1}{c}{ Cap } & \multicolumn{1}{c}{ WIP } & Backlog \\
\hline 1 & 0.25 & 0.25 & 0.1 & 1 & 2 & 9757.213922 & 23801.8098 & 23560.52941 \\
2 & 0.5 & 0.25 & 0.1 & 1 & 1 & 9656.097255 & 26617.21373 & 26274.42157 \\
3 & 0.25 & 0.5 & 0.1 & 1 & 1 & 9460.630392 & 34320.24314 & 33781.85098 \\
4 & 0.5 & 0.5 & 0.1 & 1 & 2 & 8093.935686 & 57560.5 & 55695.00196 \\
5 & 0.25 & 0.25 & 0.5 & 1 & 1 & 9953.988627 & 24304.16667 & 24264.45686 \\
6 & 0.5 & 0.25 & 0.5 & 1 & 2 & 9856.66 & 27212.73529 & 27075.70588 \\
7 & 0.25 & 0.5 & 0.5 & 1 & 2 & 9655.281373 & 35078.42745 & 34739.01961 \\
8 & 0.5 & 0.5 & 0.5 & 1 & 1 & 8213.58451 & 60104.84118 & 58362.87843 \\
9 & 0.25 & 0.25 & 0.1 & 3 & 1 & 9722.794314 & 25520.03333 & 28975.18039 \\
10 & 0.5 & 0.25 & 0.1 & 3 & 2 & 9657.46 & 28096.50392 & 29234.61373 \\
11 & 0.25 & 0.5 & 0.1 & 3 & 2 & 9460.573725 & 36293.83137 & 36747.03922 \\
12 & 0.5 & 0.5 & 0.1 & 3 & 1 & 7875.687647 & 67670.43529 & 66515.6549 \\
13 & 0.25 & 0.25 & 0.5 & 3 & 2 & 9926.580588 & 25971.22157 & 29581.78235 \\
14 & 0.5 & 0.25 & 0.5 & 3 & 1 & 9846.167059 & 28562.17451 & 29796.00588 \\
15 & 0.25 & 0.5 & 0.5 & 3 & 1 & 9647.239608 & 36544.38824 & 36943.81765 \\
16 & 0.5 & 0.5 & 0.5 & 3 & 2 & 8013.971569 & 69362.42353 & 68602.76863 \\
\hline
\end{tabular}

The DOE was constructed and analysed using the Minitab statistical software. After elimination the non-significant interactions using the normal plots, the factorial fit of every performance measure level was generated. The full results are displayed in the Appendix. The residual plots together with the $R^{2}$ and the adjusted $R^{2}$ values confirm the validity of the analysis in terms of the normality assumption of errors and the significance of the selected parameters.

\section{Results and discussion}

In this section, the impact of the capacity scaling policy on the system performance will be explored by investigating the impact of the weights and their interaction on the capacity, WIP and backlog. Next, the impact of the marketing policy will be examined by investigating the impact of the TRT on system performance and its interaction with some of the system's parameters. Finally, on the capacity investment decisions in a variable demand environment will be examined by studying the relation between the SDT and the demand SD. The main effect plots and the interaction plots are analysed, but plots for independent parameters were excluded in this analysis.

\subsection{Deciding on the capacity scaling policy}

Figure 2 indicates that with a low value of $W_{P}$ the capacity scaling level is high and as the value of $W_{P}$ rises, the capacity scaling level decreases. This means that the more 
emphasis is placed on the capacity scaling policy on the demand (given a capable system), the less scaling effort will be required to meet the demand. This is because most of the capacity will be dedicated to the demand while limited capacity portion will be dedicated to other system internal measures. Figure 3 also shows that $W_{i}$ has the same impact on the capacity scaling level.

Figure 2 Effect plot, factor $W_{p}$ response capacity (see online version for colours)

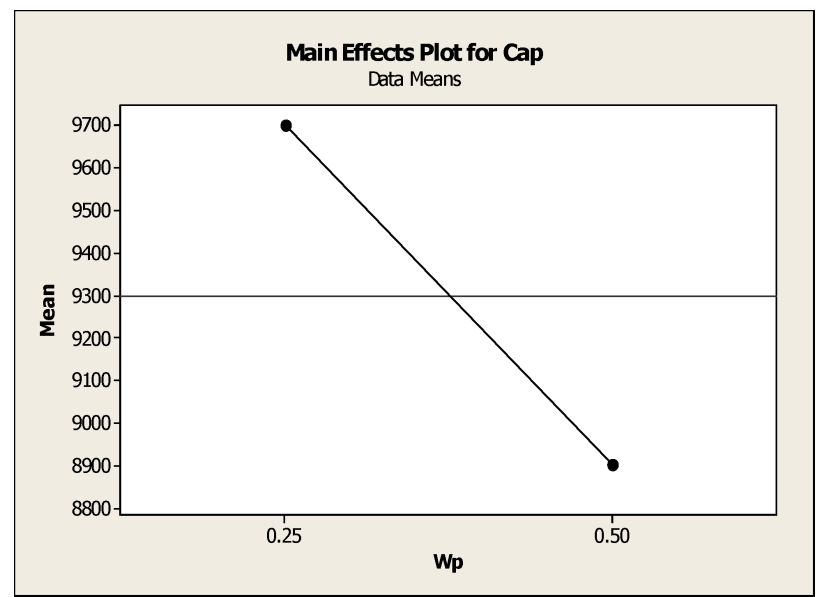

Figure 3 Effect plot, factor $W_{i}$ response capacity (see online version for colours)

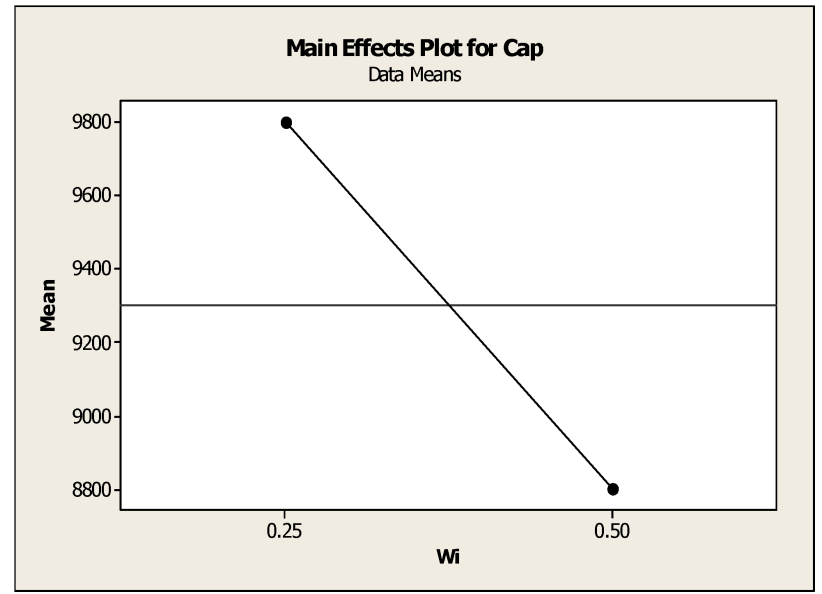

Figure 4 illustrates a scenario where both weights interact to affect the capacity scaling level. It shows that the drop in the capacity scaling level is maximised when both weights are set to 0.5 . Referring to equation (5), this scenario sets the weight of accounting for the WIP level in the capacity scaling policy equal to zero. Therefore, it can be concluded that the scaling effort and hence cost in a MTO manufacturing is minimal when the hybrid capacity scaling policy accounts only for demand and inventory levels. This conclusion also means that the more emphasise a capacity scaling policy places on accounting for internal stability (reflected in the WIP level), the higher the scaling effort and cost that would be encountered. 
Figure 4 Interaction plot, factors WP and WI and response capacity scaling level (see online version for colours)

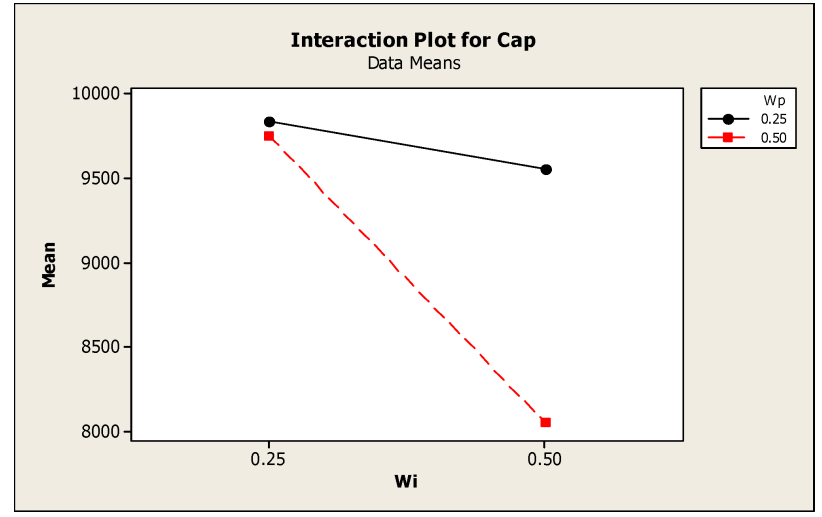

Figure 5 shows the scenario where both weights interact to impact the WIP level. This interaction confirms the previous conclusion as it shows that the higher the emphasis on fulfilling the demand or decreasing the inventory level in the capacity scaling policy, the more negative the impact on the WIP level will be. The highest negative impact, as shown in the figure, occurs when both weights are at their maximum value leaving no consideration of WIP level in the hybrid capacity scalability policy.

Figure 5 Interaction plot, factors WP and WI and response WIP level (see online version for colours)

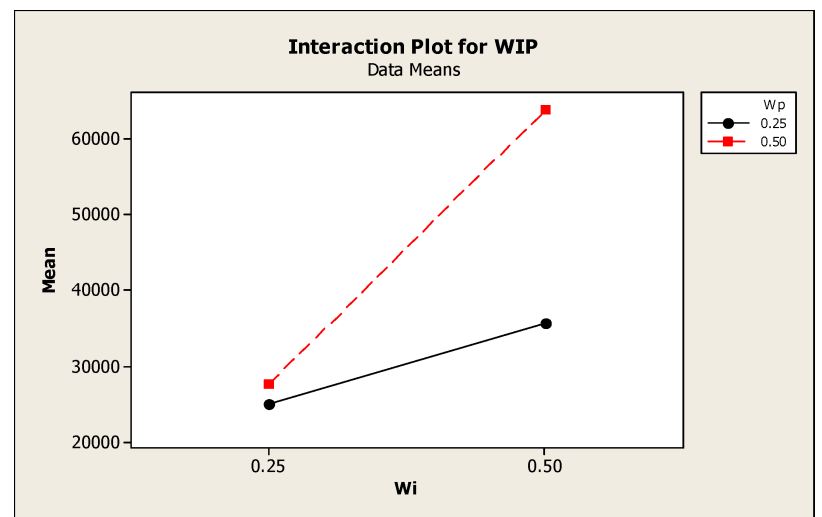

The final performance measure considered is the backlog level and Figure 6 reveals that both weights exhibit similar behaviour regarding their impact on the backlog level as to the WIP level. It is interesting to note the unexpected result that increasing the emphasis on fulfilling the demand (i.e., when $W_{P}$ have a high value) also increases the backlog level in a MOR environment. This highlights that ignoring the WIP level in any capacity scaling policy will deteriorate the responsiveness level no matter how much the focus is on fulfilling the demand. As for the inventory level, the results shows that emphasising the low inventory level in the capacity scalability policy will be at the expense of the WIP level in the system, which will in turn affect the backlog level and increase its value. 
Figure 6 Interaction plot, factors WP and WI and response backlog level (see online version for colours)

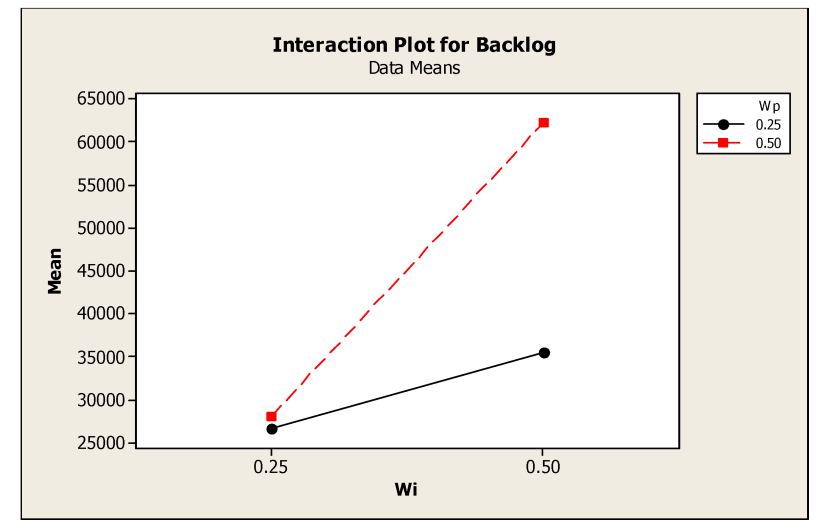

The previous discussion of how the weights of the hybrid capacity scalability policy interact with the different performance measures emphasises the importance of determining the best setting for these weights. A trade-off is clear in this manufacturing setup between two scenarios:

- reducing the capacity scaling level and its associated cost

- considering both the internal stability by reducing the WIP level as well as the responsiveness level by reducing the backlog.

However, the conducted DOE analysis proposes a method for selecting the best weights using the generated models shown in the appendix. The capacity scalability planner can set the target levels for every performance measure, and then the models are used to offer different feasible combinations of parametric settings that the planner can select from given the available resources.

\subsection{Deciding on the marketing policy}

In this analysis, the TRT is used as an indicator since responsiveness is a typical market objective for a MTO manufacturer. Figure 7(a)-(c) describes the effect of TRT on the selected performance measures. As expected, if a high responsiveness time (i.e., low TRT value) is desired, a higher capacity scaling level should be expected to maintain that responsiveness (Figure 7(a)). The low responsiveness level works in favour of reducing both the WIP level as well as the backlog level (Figure 7(b) and (c)). This presents the market planner with another trade-off decision to be made.

When high responsiveness is considered as a market policy, it is expected that any delay within the system would affect it negatively. The same is true for the capacity SDT. However, Figure 8 reveals an interesting interaction between the TRT and the SDT. As expected, at high TRT the backlog level increases as the SDT increases leading to a less responsiveness performance. However, at low TRT value, as SDT increase (which means slower scaling of capacity) the backlog level decreases leading to higher responsiveness. This is due to the dynamics of the capacity feedback loop as will be explained in Section 5.3. 
Figure 7 Effect plot, factor TRT, responses: (a) capacity; (b) backlog and (c) WIP levels (see online version for colours)

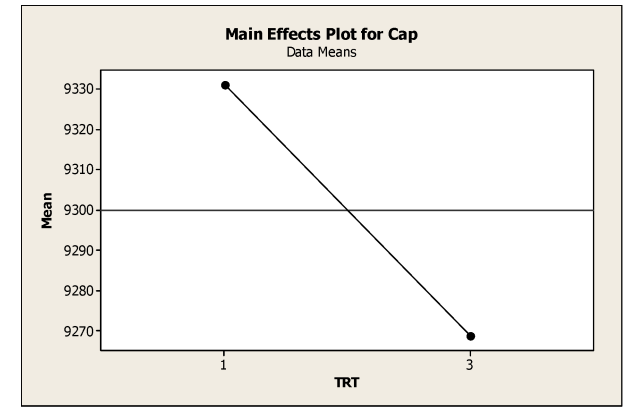

(a)

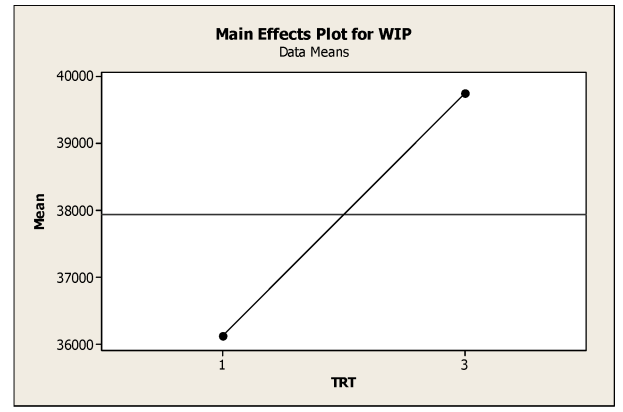

(b)

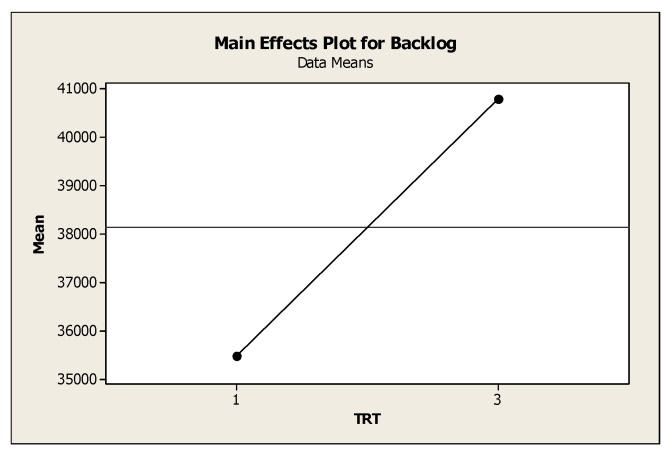

(c)

Figure 8 Interaction plot, factors TRT and SDT, response backlog level (see online version for colours)

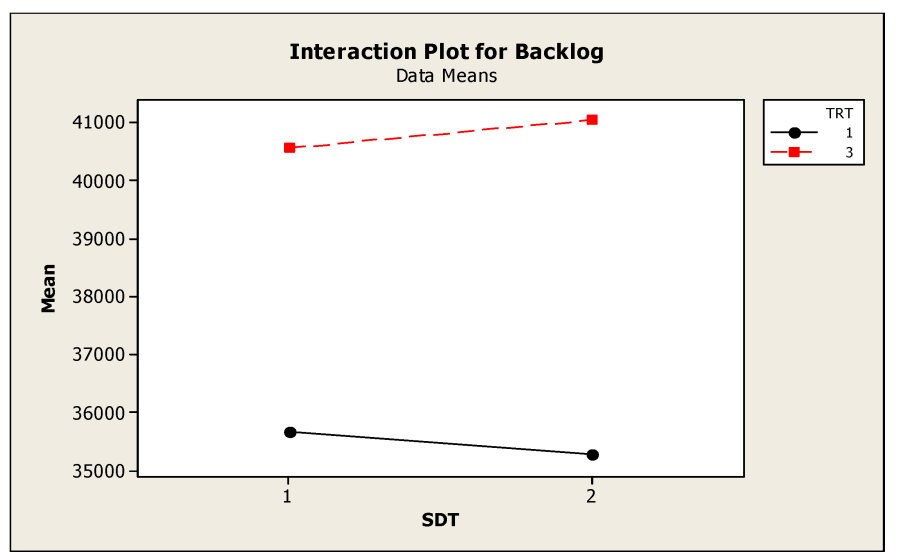

\subsection{Investigating relation between demand variation and capacity SDT}

Finally, the relation between an important parameter in capacity scaling policy (which is SDT) and the demand variation (reflected in SD) will be examined. In other words, how can the capacity planner, based on the understanding of the demand variability, decide on the timing of capacity scaling? The earlier discussion and findings about the value of 
weights guides the capacity planner regarding the magnitude of capacity scaling. The analysis in this section provides guidelines regarding its timing.

Figures 9-11 show the interaction plot between SDT and SD. The figures reveal various important observations about the dynamics of capacity scaling systems that seem opposite to the traditional wisdom of planning capacity scalability.

From Figures 9-11, it is clear that when the demand variation is high, then decreasing capacity level variation to maximise the scaling delay time is favoured (Figure 9). However, the opposite is true for WIP and backlog levels where higher SDT level increases both levels (Figures 10 and 11, respectively). This is due to the fact that higher SDT values means less capacity to be added to the system (i.e., lower capacity scaling level) but this will decrease the ability of the production system to eliminate both the internal WIP level as well as the backlog level. This will again present the capacity planner with the same trade-off question to consider.

Figure 9 Interaction plot, factors SD and SDT, response capacity level (see online version for colours)

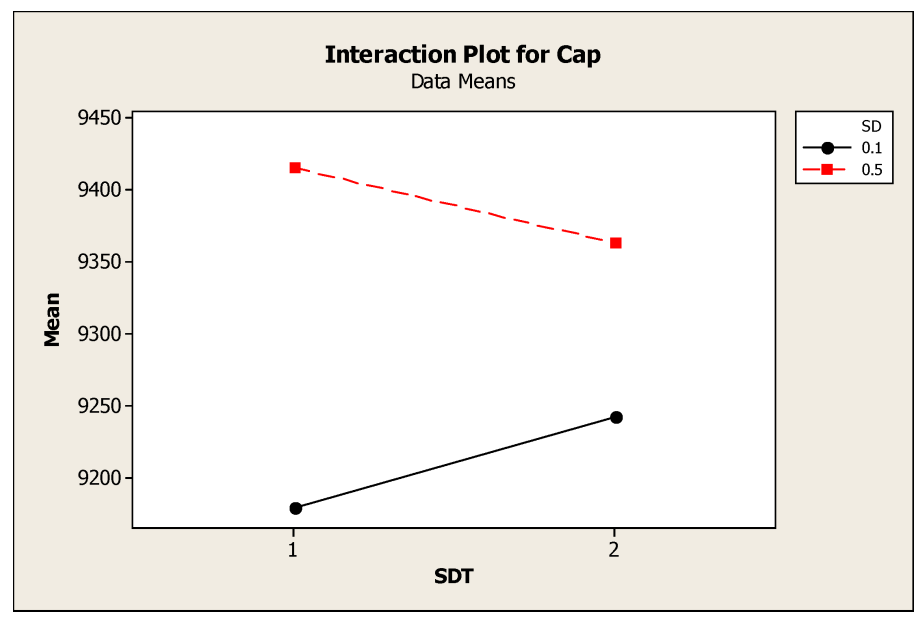

Figure 10 Interaction plot, factors SD and SDT, response WIP level (see online version for colours)

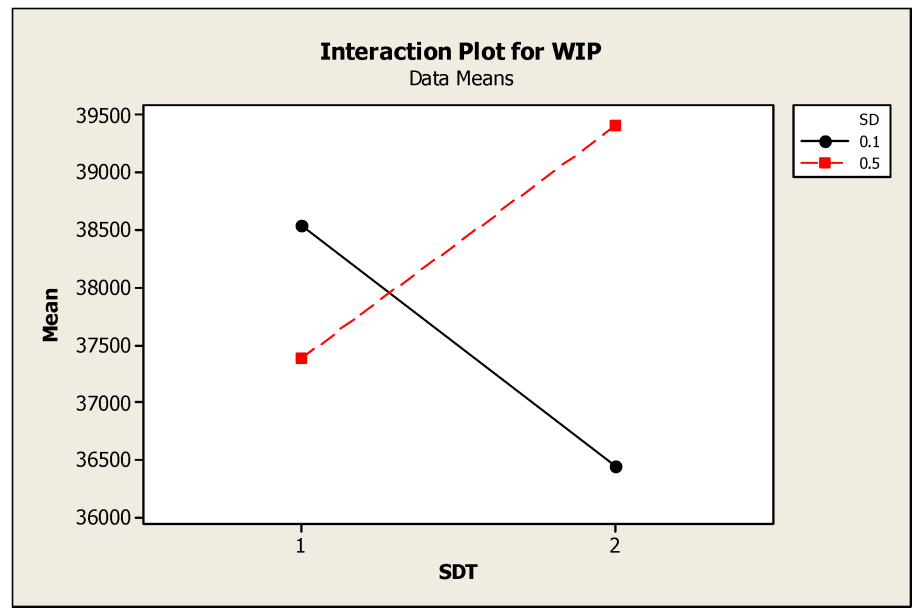


Figure 11 Interaction plot, factors SD and SDT, response backlog level (see online version for colours)

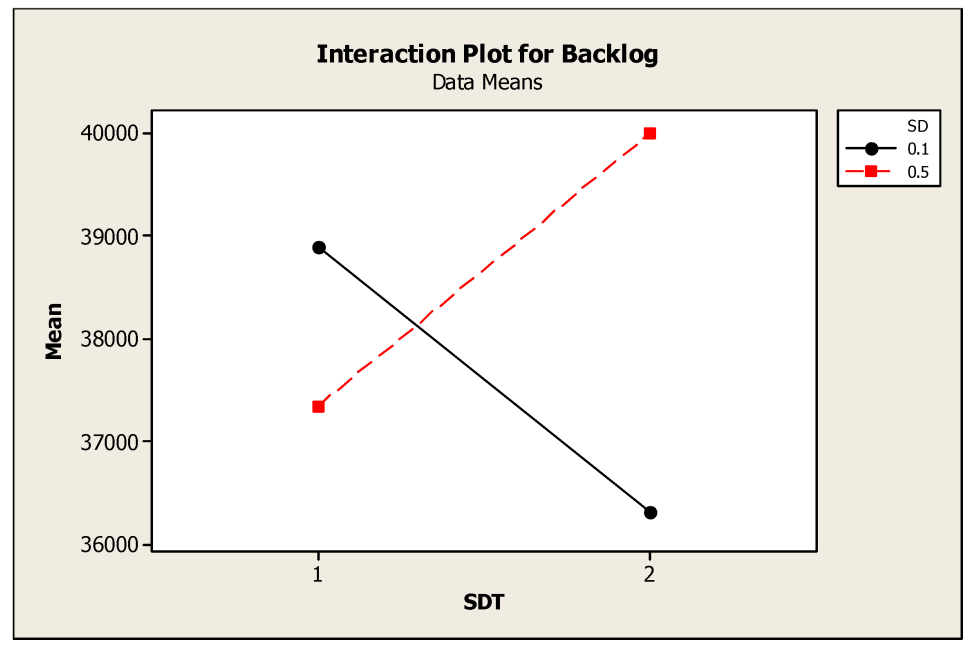

However, when the demand variability is low, the results show a unique behaviour. The capacity scaling becomes lower with low SDT value (Figure 9) although this means that a higher portion of the required capacity is added to the system. In addition, the WIP and the backlog will have lower levels with high SDT value although this means that less capacity is added to the system (Figures 10 and 11, respectively).

A thorough understanding the dynamics of these scalable systems, which include multiple system parameters, offers an explanation for this behaviour and its reasons. The capacity level changes based on a feedback mechanism as explained earlier in Section 3. The gain of this feedback is controlled mainly by the SDT, which decides on the portion of the required capacity to be removed or added. However, this is not the only feedback loop in the system, as there is the inventory compensating feedback that in this example has an adjustment time of 2 weeks. When the SDT is less than Inventory Adjustment Time (IAT), as in this case study, the system will experience two feedbacks with delay and thus more oscillation would occur and higher WIP and backlog levels (Sterman, 2000). Once the delay of the capacity scalability feedback loop equals that of the IAT, the system will practically have one dominant delay time of the capacity scalability feedback loop and thus lower WIP and backlog levels. It is important to note that these oscillations appear when the system is subjected to high variability. This is why at low demand variation (within the selected setup of this application) high scaling capacity decisions generate unfavourable SD that would negatively affect the overall performance of the system. Such behaviour and conclusion would have never been understood without exploring and modelling the dynamic interaction between the SDT and the demand variation.

\section{Summary and conclusion}

DOE techniques were used for evaluating the performance of capacity scalability system in a reconfigurable MTO system. A mathematical model is formulated using SD to 
capture both the market as well as the operational dynamics. The hybrid capacity scaling policy that mutually considers multiple system parameters (demand, WIP and inventory) is at the core of the proposed model and analysis. A real case study of a MTO furniture manufacturer was simulated and used to apply the proposed model. The developed model and case study simulation analysis were used to:

- Gain deeper insights into the relative importance of the multiple system parameters in the hybrid capacity scalability policy. This was achieved through investigating the impact of different capacity scaling weights over three performance measures (capacity level, WIP level and backlog level).

- Determine the impact of the different marketing policies on the selected performance measures. This was achieved through investigating the impact of different responsiveness target times.

- Study the effect of synchronising both capacity and marketing policies to achieve the best performance in similar MTO systems.

- Investigate the relation between demand variation and capacity SDT to provide the planner with knowledge and guidelines to help determine the magnitude and timing of the required capacity increments/reduction for different demand scenarios.

The main conclusions of the conducted analysis are:

1 Policies aiming only at minimising the investment in capacity scaling should minimise the effort to reduce WIP level while focusing mainly on fulfilling demand and minimising inventory.

2 If the MTO manufacturer would like to decrease backlog and have higher responsiveness, the capacity scaling policy should place more emphasis on accounting for internal stability and reducing the WIP level. It was shown that this would happen at the expense of dedicating more capacity to fulfilling the demand.

3 The marketing policy should consider the operational goals when deciding on the desired responsiveness level. It has been shown that deciding on the TRT is a trade off between the cost of investing in the system capacity and reducing the backlog level to increase responsiveness.

4 Determining the capacity SDT is a critical decision for capacity scalability planners as it highly affects the dynamics of MTO systems that account for various systems parameters in their capacity policies. Results indicated that some settings of the system parameters (specifically IAT) would make SDT, unexpectedly, act in favour of system responsiveness. The analysis showed that at lower TRT, higher values of SDT would decrease the backlog level. In addition, at lower demand variation scenarios, higher values of SDT also decrease both backlog as well as WIP levels. Thus, it is important for the capacity planner to realise that SDT selection does not only affect system parameters but also can not be set in isolation from the inventory feedback delay.

The general abstraction of the proposed model's parameters together with the presented parametric approach analysis makes the previous conclusions relevant and applicable to 
similar dynamic capacity systems in MTO environments through adjusting the demand (SD) and the other system's parameters to reflect other MTO applications.

In summary, today's dynamic environment, where both the demand as well as the manufacturing system structure continuously changes, successful enterprises should fully understand the dynamic interaction between the various system parameters. A clear insight into the relationship between the decision parameters of different policies and system performance measures would help optimise these policies and inform efficient trade-off decisions. Finally, in a dynamic MTO environment, marketing polices cannot be designed in isolation form capacity scaling policies. Inter-functional integration between capacity and marketing policies will guarantee an overall efficient system's performance. Future work would focus on investigating more interactions between parameters and include more system performance measures for the overall system assessment.

\section{References}

Anderson, E., Morrice, D. and Lundeen, G. (2005) 'The 'physics' of capacity and backlog management in service and custom manufacturing supply chains', System Dynamics Review, Vol. 22, No. 3, pp.217-247.

Deif, A. and ElMaraghy, H. (2007) 'Assessing capacity scalability policies in RMS using system dynamics', International Journal of Flexible Manufacturing System, Special Issue on Dynamic Capacity, Vol. 19, pp.128-150.

Deif, A. and ElMaraghy, H. (2009) 'Modeling and analysis of dynamic capacity complexity in multi-stage production', Journal of Production Planning and Control, Vol. 20, No. 8, pp.737-749.

ElMaraghy, H. (2005) 'Flexible and reconfigurable manufacturing systems paradigms', International Journal of Flexible Manufacturing Systems, Special Issue on Reconfigurable Manufacturing Systems, Vol. 17, No. 4, pp.261-276.

Evans, G. and Naim, M. (1994) 'Dynamics of capacity constrained supply chains', Proceedings of International System Dynamics Conference, Stirling, pp.28-35.

Forrester, J.W. (1961) Industrial Dynamics, MIT Press, Cambridge, USA.

Goncalves, P., Hines, J. and Sterman, J. (2005) 'The impact of endogenous demand on push-pull production systems', System Dynamics Review, Vol. 22, No. 3, pp.217-247.

Helo, P. (2000) 'Dynamic modeling of surge effect and capacity limitation in supply chains', International Journal of Production Research, Vol. 38, No. 17, pp.4521-4533.

Higuchi, T. and Troutt, M.D. (2004) 'Dynamic simulation of the supply chain for a short lifecycle product - lessons from the Tamagotchi case', Computers and Operations Research, Vol. 31, pp.1097-1114.

Holt, C.C., Modigliani, F., Muth, J.F. and Simon, H.A. (1960) Planning Production, Inventories, and Work force, Prentice-Hall, Englewood Cliffs, NJ.

Huh, W.T., Roundy, R.O. and Cakanyildirim, M. (2006) 'A general strategic capacity planning model under demand uncertainty', Naval Research Logistics, Vol. 2, pp.137-150.

John, S., Towill, D.R. and Naim, M. (1994) 'Dynamic analysis of a WIP compensated support system', International Journal of Manufacturing System Design, Vol. 1, pp.283-297.

Kamath, N. and Roy, R. (2007) 'Capacity augmentation of a supply chain for a short lifcycle product: a system dynamics framework', European Journal of Operational Research, Vol. 179, pp.334-351.

Koren, Y., Heisel U., Jovane, F. and Moriwaki, T. (1999) 'Reconfigurable manufacturing system', Annals of CIRP, Vol. 48, No. 2, pp.1-6. 
Kotha, S. and Swamidass, P.M. (2000) 'Strategy, advanced manufacturing technology, and performance: empirical evidence from US manufacturing .rms', Journal of Operations Management, Vol. 18, No. 3, pp.257-277.

Luss, H. (1982) 'Operation research and capacity expansion problems: a survey', Operation Research, Vol. 3, No. 5, pp.907-947.

Manne Alan, S. (1967) Investments for Capacity Expansion, Size, Location, and Time-phasing, The MIT Press, Cambridge, MA.

Mehrabi, M., Ulsoy, G. and Koren, Y. (2000) 'Reconfigurable manufacturing systems: key to future manufacturing', Journal of Intelligent Manufacturing, Vol. 11, pp.403-419.

Sethi, S.P. and Thompson, G.L. (2000) Optimal Control Theory: Applications to Management Science and Economics, Kluwer, Boston, MA.

Shapiro, B. (1977) 'Can marketing and manufacturing coexist?', Harvard Business Review, Vol. 55, pp.104-114.

Sterman, J.D. (2000) Business Dynamic - Systems Thinking and Modeling for A Complex World, McGraw-Hill, NY.

Tomlin, B. (1999) Supply Chain Design: Capacity, Flexibility and Wholesale Price Strategies, PhD Dissertation, Sloan School of Management, MIT, Cambridge.

Ulsoy, G. and Yazgac, T. (1995) 'Joint decision making for production and marketing', International Journal of Production Research, Vol. 33, pp.2277-2293.

Vlachos, D., Georgiadis, P. and Iakovou, E. (2007) 'A system dynamics model for dynamic capacity planning of remanufacturing in closed-loop supply chains', Computers and Operations Research, Vol. 34, pp.367-394.

Wiendahl, H-P., ElMaraghy, H.A., Nyhuis, P., Zaeh, M., Wiendahl, H-H., Duffie, N. and Kolakowski, M. (2007) 'Changeable manufacturing: classification, design, operation, keynote paper', CIRP Annals, Vol. 56, No. 2, pp.1-6.

\section{Appendix}

Normal plots before eliminating insignificant parameters (see online version for colours)

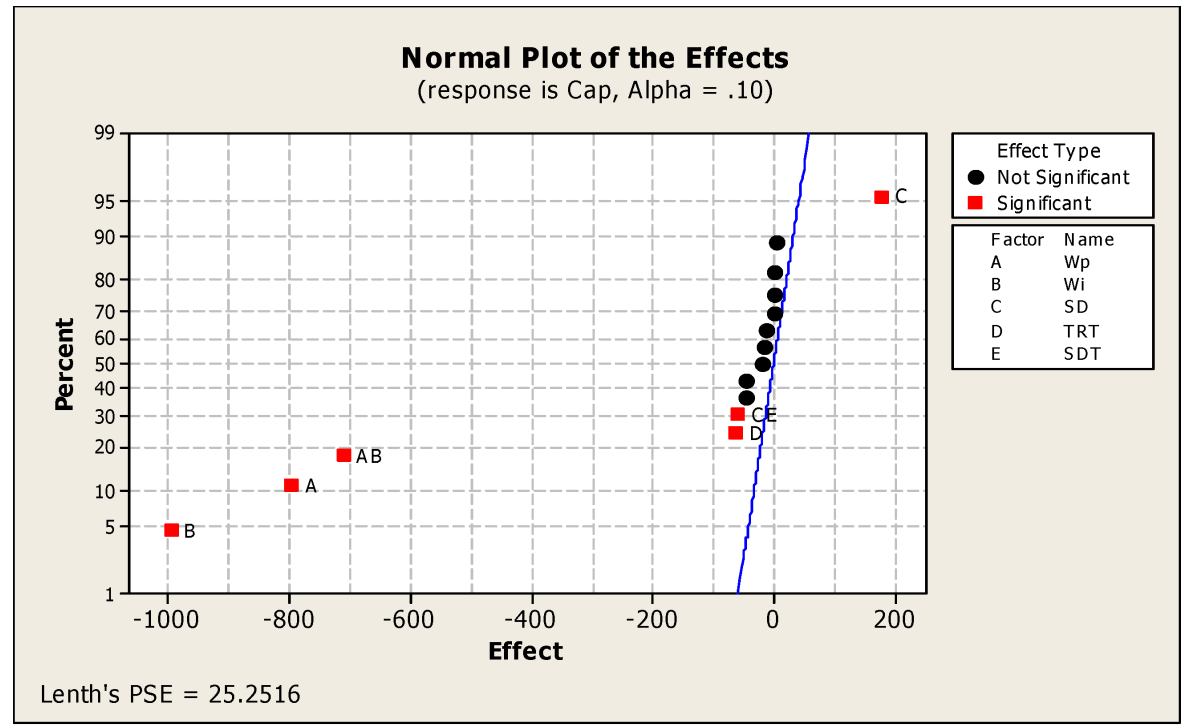



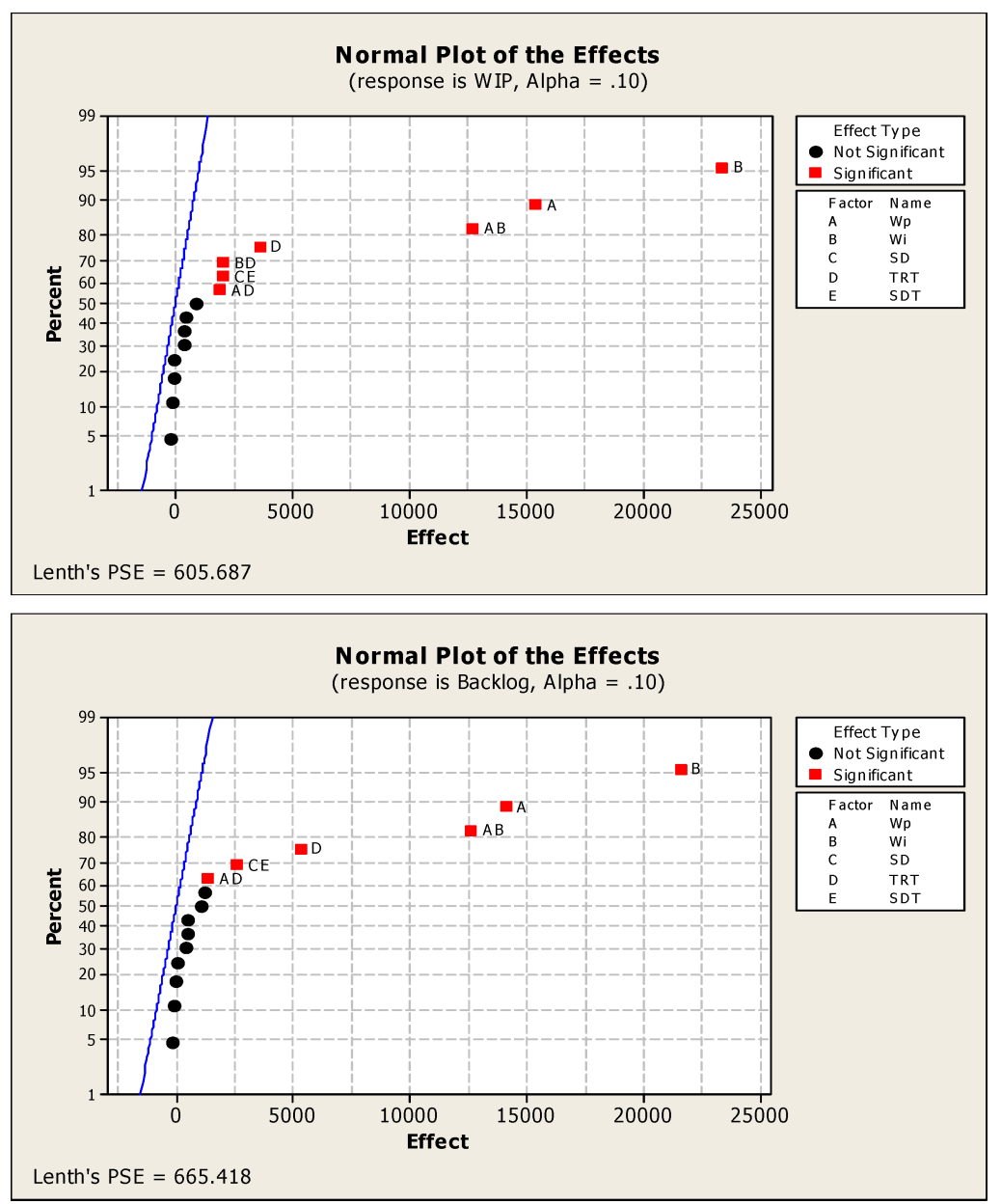

Normal plots after eliminating insignificant parameters (see online version for colours)

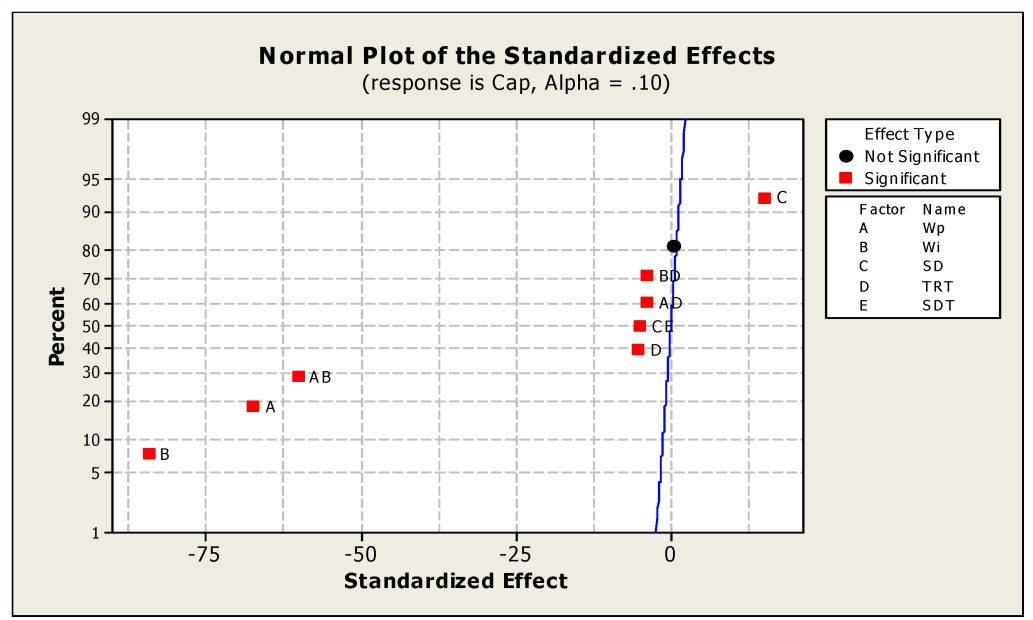



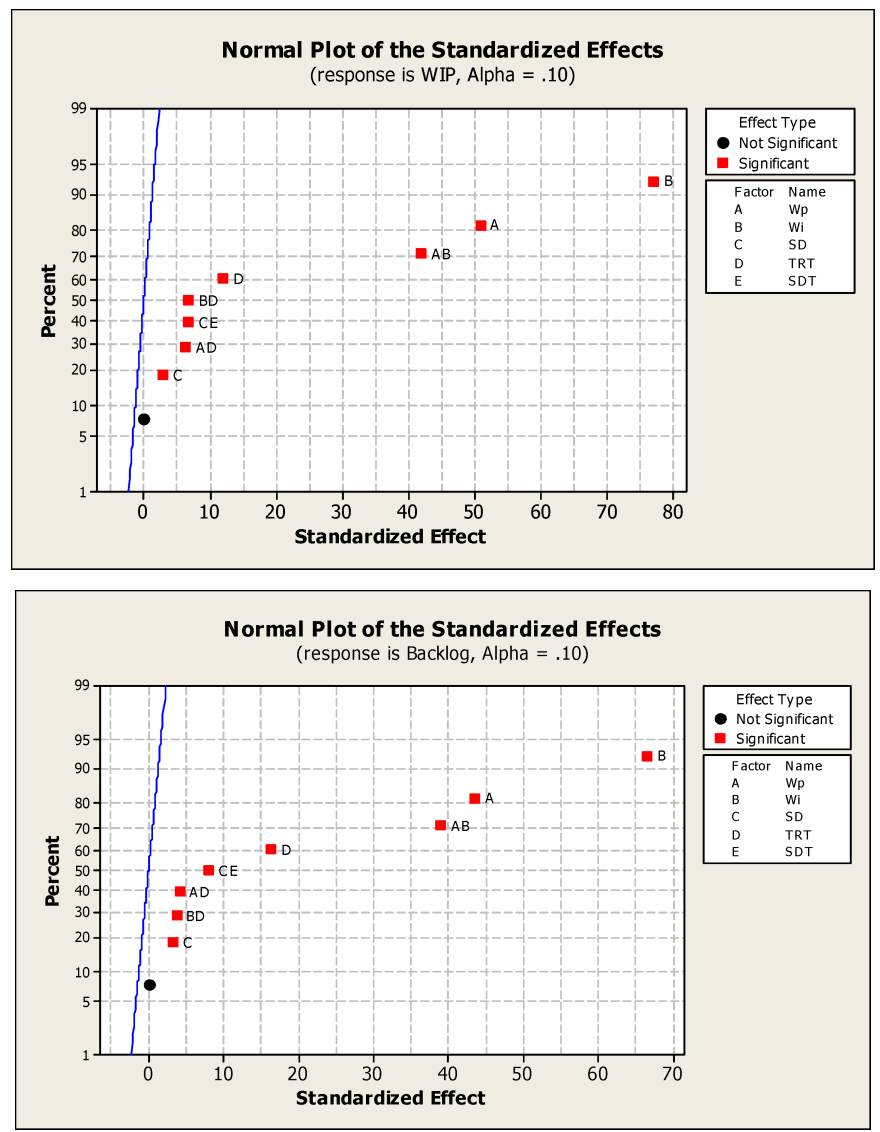

Factorial fit, $P$ values, $R^{2}$ and the adjusted $R^{2}$ values

Factorial fit: cap vs. $W_{p}, W_{i}, S D, T R T, S D T$

Estimated effects and coefficients for cap (coded units)

\begin{tabular}{lrrrrc}
\hline Term & Effect & Coef. & SE coef. & $T$ & $P$ \\
\hline Constant & & 9299.9 & 5.913 & 1572.68 & 0.000 \\
$W_{p}$ & -796.3 & -398.2 & 5.913 & -67.33 & 0.000 \\
$W_{i}$ & -994.5 & -497.3 & 5.913 & -84.09 & 0.000 \\
SD & 178.6 & 89.3 & 5.913 & 15.10 & 0.000 \\
$T R T$ & -62.1 & -31.1 & 5.913 & -5.25 & 0.002 \\
$S D T$ & 5.7 & 2.8 & 5.913 & 0.48 & 0.648 \\
$W_{p}{ }^{*} W_{i}$ & -710.3 & -355.1 & 5.913 & -60.06 & 0.000 \\
$W_{p}{ }^{*} T R T$ & -44.6 & -22.3 & 5.913 & -3.77 & 0.009 \\
$W_{i}^{*} T R T$ & -44.4 & -22.2 & 5.913 & -3.75 & 0.009 \\
SD*SDT & -57.8 & -28.9 & 5.913 & -4.89 & 0.003 \\
\hline
\end{tabular}

$\mathrm{S}=23.6535 \quad$ PRESS $=23871.5$

$\mathrm{R}-\mathrm{Sq}=99.96 \% \quad \mathrm{R}-\mathrm{Sq}(\mathrm{pred})=99.73 \% \mathrm{R}-\mathrm{Sq}(\mathrm{adj})=99.90 \%$. 
Factorial fit: backlog vs. Wp, Wi, SD, TRT, SDT

Estimated effects and coefficients for backlog (coded units)

\begin{tabular}{lcrcrc}
\hline Term & Effect & Coef. & SE coef. & $T$ & $P$ \\
\hline Constant & & 38134.4 & 161.9 & 235.61 & 0.000 \\
$W_{p}$ & 14120.4 & 7060.2 & 161.9 & 43.62 & 0.000 \\
$W_{i}$ & 21578.2 & 10789.1 & 161.9 & 66.66 & 0.000 \\
SD & 1072.8 & 536.4 & 161.9 & 3.31 & 0.016 \\
TRT & 5330.4 & 2665.2 & 161.9 & 16.47 & 0.000 \\
SDT & 40.3 & 20.1 & 161.9 & 0.12 & 0.905 \\
$W_{p}{ }^{*} W_{i}$ & 12620.7 & 6310.4 & 161.9 & 38.99 & 0.000 \\
$W_{p}{ }^{*}$ TRT & 1354.9 & 677.4 & 161.9 & 4.19 & 0.006 \\
$W_{i}^{*}$ TRT & 1227.3 & 613.6 & 161.9 & 3.79 & 0.009 \\
SD*SDT & 2617.8 & 1308.9 & 161.9 & 8.09 & 0.000 \\
\hline
\end{tabular}

$\mathrm{S}=647.404 \quad$ PRESS $=17882936$

$\mathrm{R}-\mathrm{Sq}=99.93 \% \quad \mathrm{R}-\mathrm{Sq}($ pred $)=99.48 \% \quad \mathrm{R}-\mathrm{Sq}($ adj $)=99.82 \%$

Factorial Fit: WIP vs. Wp, Wi, SD, TRT, SDT

Estimated effects and coefficients for WIP (coded units)

\begin{tabular}{lcrcrc}
\hline Term & Effect & Coef. & SE coef. & $T$ & $P$ \\
\hline Constant & & 37938.8 & 151.5 & 250.48 & 0.000 \\
$W_{p}$ & 15419.1 & 7709.5 & 151.5 & 50.90 & 0.000 \\
$W_{i}$ & 23356.2 & 11678.1 & 151.5 & 77.10 & 0.000 \\
SD & 907.5 & 453.7 & 151.5 & 3.00 & 0.024 \\
TRT & 3627.6 & 1813.8 & 151.5 & 11.98 & 0.000 \\
SDT & -33.3 & -16.6 & 151.5 & -0.11 & 0.916 \\
$W_{p}{ }^{*} W_{i}$ & 12696.2 & 6348.1 & 151.5 & 41.91 & 0.000 \\
$W_{p}{ }^{*}$ TRT & 1921.4 & 960.7 & 151.5 & 6.34 & 0.001 \\
$W_{i}^{*}$ TRT & 2074.1 & 1037.1 & 151.5 & 6.85 & 0.009 \\
SD*SDT & 2060.6 & 1030.3 & 151.5 & 6.80 & 0.000 \\
\hline
\end{tabular}

$\mathrm{S}=605.846 \quad$ PRESS $=15660793$

$\mathrm{R}-\mathrm{Sq}=99.94 \% \quad \mathrm{R}-\mathrm{Sq}($ pred $)=99.60 \% \quad \mathrm{R}-\mathrm{Sq}(\operatorname{adj})=99.86 \%$.

Residual plots (see online version for colours)

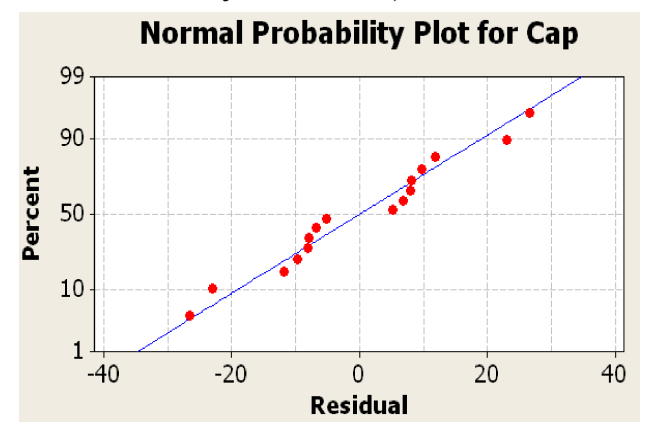




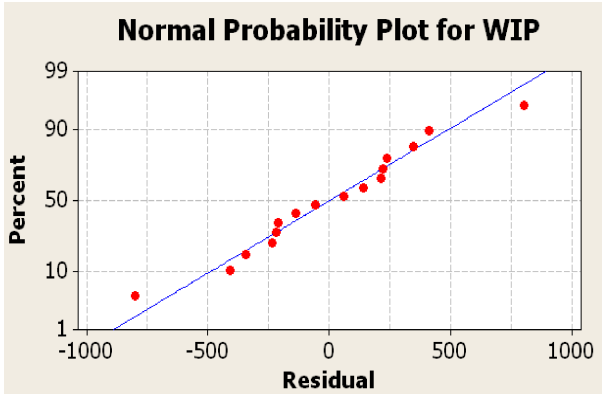

Normal Probability Plot for Backlog

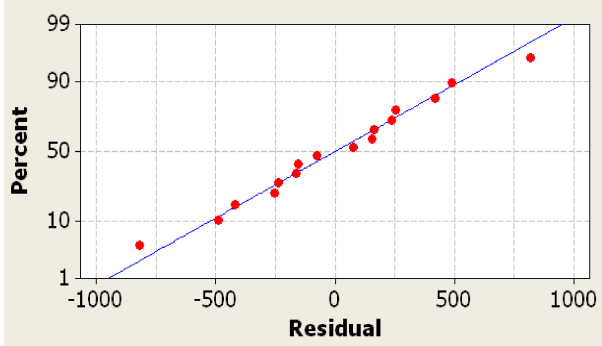

